\title{
Computational modeling of dehydration of mushroom
}

\begin{abstract}
Mushrooms are a group of edible macroscopic fungi with high nutritional value, flavor and taste. Mushrooms are highly perishable in nature leading to low shelf-life causing economic losses to the producers. Dehydration is one of the oldest and widely used methods to increase the shelf life of mushroom. During dehydration, it is difficult to monitor the temperature and moisture content. Hence, a 2D finite element model was developed by considering the simultaneous heat and mass transfer along with phase change effect during dehydration for predicting the temperature and moisture profiles. The model predictions were validated with the experimental measurements of temperature and moisture content of mushroom dried at $54 \pm 1{ }^{\circ} \mathrm{C}$ in a cabinet hair dryer. Drying was carried out for a maximum period of 5 hours. The temperature and moisture content profiles, effect of convection and conduction heating, slowest heating zone (SHZ) were studied. The temperature profile of mushroom shows initial exponential increase followed by constant temperature during the drying process. Mushroom head portion showed higher moisture content when compared to stem as it also appears to be the slowest heating zone.
\end{abstract}

Keywords: mushroom, dehydration, moisture content, slowest heating zone, finite element modeling
Volume 6 Issue 3 - 2018

\author{
ChoudharyA,' Gopirajah R2 \\ 'Food Engineering Department, CSIR-Central Food \\ Technological research Institute, India \\ ${ }^{2}$ Food science Department, Cornell University, USA
}

Correspondence: Gopirajah R, Postdoc Associate, Food Engineering Department, Cornell University, Ithaca, NY, US I4850 Email r.gopirajah@gmail.com

Received: April 19, 2018| Published: May 232018
Abbreviations: $a_{w}$, Water activity; $h_{L}$, heat transfer coefficient $\left(\mathrm{W} / \mathrm{m}^{2} \mathrm{~K}\right) ; R H$, relative humidity $(\%) ; d T$, temperature difference in which phase change occurs $(\mathrm{K}) ; t$, time(s); $\lambda$, Latent heat of phase change $\left(\mathrm{J} / \mathrm{m}^{3}\right)$; SHZ, slowest heating zone

\section{Introduction}

Fruits and vegetables owing to their highly perishable nature need to be processed to reduce wastage and also to make them available for off-season consumption. Dried fruits and vegetables are an important sector in the food ingredient market. ${ }^{1}$ Dehydrated fruits and vegetables such as mushroom, carrot, corn, pineapple, banana, garlic, and so on are extensively used in a variety of food formulations. Mushroom export from India increased from 4000tons in 1985-86 to 30,000ton in 1996-97. ${ }^{2}$ Mushrooms are mostly traded in the processed form ${ }^{3}$ and serve the nutritional needs of the population in a developing country. This is attributed to their delicious flavor, low calorific value, high protein content (20-40\% dry basis), richness in vitamins of B-group (B-12), minerals and zero cholesterol content. ${ }^{4}$ Out of 38,000 varieties of mushroom known to human, at least 25 of the known species have been considered as edible food. White button mushroom (Agaricus bisporus) is the most widely cultivated and consumed mushroom throughout the world and contributes about $40 \%$ of the total world production of mushroom. ${ }^{3}$ The perishable nature of mushroom leads to numerous morphological and physiological changes causing enormous economic losses to the producers.

Drying is an important unit operation for extending the shelf life of mushroom. Drying involves removal of water from the product thus making it unavailable to support the growth of microorganisms. A number of drying methods can be used such as sun drying, cabinet air drying, vacuum drying, microwave drying, freeze drying, etc. These methods can be used individually or in combination. Selection of suitable drying technique is quintessential to a successful operation, since mushrooms are heat sensitive. Mushroom growers continue to dry mushroom under sun, which yields unhygienic and poor quality product. ${ }^{3}$ Vacuum drying takes very long time due to lower diffusion coefficient when compared to all other drying methods. ${ }^{4}$ Microwave drying is deemed unsuitable for drying of mushroom as there is no temperature control, and it also leads to charring of mushroom particularly at edges ${ }^{4}$ Freeze drying produces a high quality product, but being an expensive process, its application to mushroom drying is limited. ${ }^{3}$

In the cabinet drying, mushroom is heated externally from the air by convection and internally by conduction. As a result, the surface moisture leaves first and then gradually the heat penetrates inside the mushroom through its surface. As the heat penetrates, there is a simultaneous diffusion of water vapor from the core of the mushroom to the outer surface. ${ }^{5}$ During initial stages of drying, rapid moisture loss is observed due to the high amount of surface moisture present in mushroom. As drying time progresses, most of the unbound moisture is removed from the mushroom. Also, the rate of drying decreases as drying time increases.

A lot of preliminary work has been reported to increase the shelflife of mushrooms by using different post harvesting techniques. However, there was scanty work in the literature regarding modeling of such techniques. Moreover, earlier modeling attempts are limited to mathematical modeling of drying process and most of them are generalized to food products such as grapes, potato, onion, etc. ${ }^{5-8}$ Recently, Lespinard et al. ${ }^{9}$ developed a model for blanching of mushroom taking into account the heat transfer occurring during blanching. However, no efforts have been made towards the development of a 2D finite element model (FEM) for dehydration of mushroom taking into account the simultaneous heat and mass transfer during drying. The model formulated can be used as a tool for optimization of drying process by determining effective time and temperature combination or for evaluating the effect of modification in the process variables. 
Hence, this work was aimed to develop a finite element model with incorporation of phase change during dehydration of mushroom in a cabinet-air-dryer to study the temperature and moisture profiles inside the mushroom.

\section{Experimental details}

Freshly harvested white button mushrooms were purchased from the local greengrocers. They were sorted manually based on shape, size and color before processing. Dimensionally similar mushroom were selected for the experiments. The dimension of these mushrooms was calculated using vernier calipers (Forbes) with an accuracy of $0.02 \mathrm{~mm}$. All the mushrooms were washed thoroughly to remove soil impurities. Two mushrooms viz. sample 1 (S1) and sample 2 (S2) of approximately same dimensions and weight were chosen. The selected samples were then placed in a cabinet-air-dryer (Industrial \& laboratory tools corporation, Chennai Serial No. S1016), dried at a temperature of $54 \pm 1^{\circ} \mathrm{C}$. Mushroom S1 was analyzed for moisture content, S2 for temperature profile. Figure 1 shows the schematic arrangement of the experimental setup.

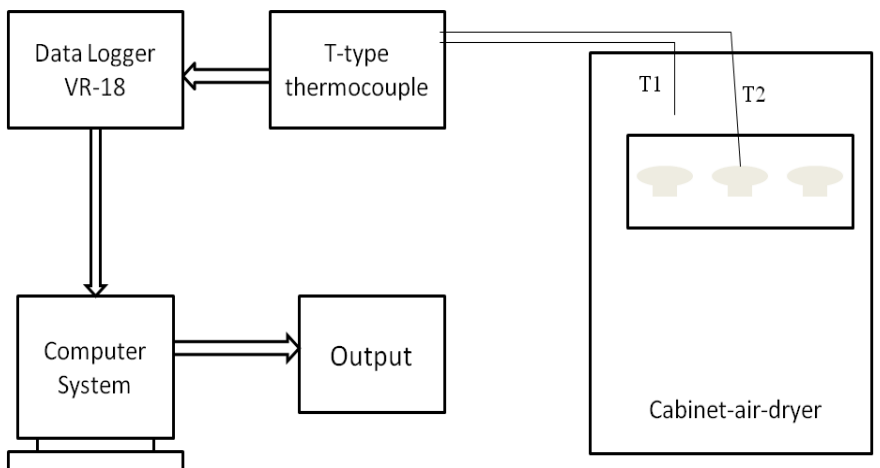

Figure I Schematic arrangement of the experimental setup.

\section{Moisture content analysis}

The initial weight of the mushroom $\mathrm{S} 1$ was measured before placing it into the dryer maintained at $54 \pm 1^{\circ} \mathrm{C}$ and at regular intervals of 30minutes mushroom was weighed on an electronic balance (Contech CA-123). Drying was carried out for a period of 5hours. To determine the bone dry weight of mushroom S1, it was put inside a hot air oven maintained at $100^{\circ} \mathrm{C}$ to dry overnight (16hours). The bone dry weight of the sample was measured and used to calculate the initial moisture content on dry basis (gram $\mathrm{H}_{2} \mathrm{O}$ /gram dry weight).

\section{Temperature profile determination}

Temperature inside the mushroom S2 was measured using two calibrated T-type thermocouples. One thermocouple was inserted in the geometric centre of the mushroom head portion and another at the geometric centre of the stem of mushroom. The temperature inside the cabinet was monitored using T-type thermocouple, which was placed very close to the mushroom. All the thermocouples were connected to the data logger (VR-18, Brainchild Electronics Co. Ltd.) and recorded at regular intervals of $30 \mathrm{~s}$ throughout the drying process.

\section{Modeling formulations}

This model is based on the following assumptions: (i) shrinkage is negligible; (ii) material properties such as specific heat, thermal conductivity and porosity are constant, and (iii) material is isotropic.

\section{Governing equations}

Heat balance equation:

$$
\rho C_{p} \frac{\partial T}{\partial t}=\nabla \cdot(k \nabla T)
$$

Where, $\rho-$ Density $\left(\mathrm{kg} / \mathrm{m}^{3}\right) ; C_{P}-$ Specific heat $(\mathrm{J} / \mathrm{kg} \mathrm{K}) ; \mathrm{T}-$ Temperature (K)

Mass balance equation:

$$
\frac{\partial W}{\partial t}=\nabla \cdot(D \nabla W)
$$

Where, $W$-Water content $(\mathrm{kg} / \mathrm{kg}) ; D$-Water (liquid or vapor) diffusion coefficient of mushroom $\left(\mathrm{m}^{2} / \mathrm{s}\right)$

\section{Boundary conditions for heat and mass transfer}

Figure 2 shows the geometry of mushroom and the meshed geometry (consisting of 9936 elements), respectively. Mushroom was placed on a stainless steel plate during the experiment. Heat transfer at the top and lateral surfaces (external) by convection is balanced with internal conduction heating. Hence, the corresponding boundary condition for equation (1) is given by Wang \& Brennan ${ }^{6}$ follows:

$$
-k \nabla T=L_{v} D \rho \nabla W+h\left(T_{S}-T_{a m b}\right)
$$

Where, k-Thermal conductivity $(\mathrm{W} / \mathrm{m} \cdot \mathrm{K})$; T-Temperature $(\mathrm{K})$; D-Water (liquid or vapor) diffusion coefficient of mushroom $\left(\mathrm{m}^{2} / \mathrm{s}\right)$; $\rho$ - Density $\left(\mathrm{kg} / \mathrm{m}^{3}\right) ; W$-Water content $(\mathrm{kg} / \mathrm{kg}) ; \mathrm{S}$-solid or surface

$L_{v} D \rho \nabla W$ denotes the quantity of heat required to evaporate the moisture through unit area. Moisture transport through mushroom surface is balanced by convective flux as given by the equation below,

$$
-D \rho_{B} \nabla W=K_{g}\left(P_{S}-P_{a m b}\right)
$$

Where, $P_{S}=a_{w} P_{\text {sat }}\left(T_{S}\right)$ and $P_{a m b}=(R H / 100) \cdot P_{s a t}\left(T_{a m b}\right) K_{g}-$ Mass transfer coefficient

Equations for $P_{\text {sat }}\left(T_{a m b}\right)$ and $P_{\text {sat }}\left(T_{\text {amb }}\right)$ were taken from Zanoni et al. ${ }^{10}$ and $\mathrm{a}_{\mathrm{w}}$ is defined from Combs (2004). Density $(\rho)$ of mushroom increases with the decrease in moisture content. Hence, it was included as a function of moisture content. The data for variation of density with change in moisture content was taken from Boukouvalas et al. ${ }^{11}$ Effective moisture diffusivity (D) for mushroom was given as $5.065 \times 10^{-9} \mathrm{~m}^{2} \mathrm{~s}^{-1} .{ }^{12}$ Thermo-physical properties of mushroom such as specific heat and thermal conductivity were given as a constant. Lespinard et al. ${ }^{9}$ proposed the specific heat $\left(\mathrm{C}_{\mathrm{p}}\right)$ as $3883 \mathrm{~J} \mathrm{Kg}^{-10} \mathrm{C}$ and thermal conductivity $(\mathrm{k})$ of mushroom as $0.4324 \mathrm{~W} \mathrm{~m}{ }^{-1}{ }^{\circ} \mathrm{C}$.

Heat transfer coefficient $\left(h_{L}\right)$ was included in the model using the following expression. ${ }^{13}$

$$
N_{S h}=\frac{K_{g} \times d i a}{D}=\left[4+1.21(N \operatorname{Re} \times N S c)^{0.67}\right]^{0.5}
$$

where, dia is the diameter of the mushroom head portion in meters. Prandtl number $\left(\mathrm{N}_{\mathrm{pr}}\right)$ was determined taking into consideration the standard thermal properties of air at $54^{\circ} \mathrm{C}$.

Mass transfer coefficient $\left(\mathrm{K}_{\mathrm{g}}\right)$ governs the rate of moisture transfer from the mushroom to the free air stream. It was included in the model with the help of Sherwood number $\left(\mathrm{N}_{\mathrm{sh}}\right)$. The head of the mushroom is spherical and due to its large size, it will determine the overall rate of 
mass transfer. Hence, Sherwood number was calculated by assuming mushroom as a sphere under forced convection (Perry's Chemical Engineers' Handbook).

$$
N_{S h}=\frac{K_{g} \times d i a}{D}=\left[4+1.21(N \operatorname{Re} \times N S c)^{0.67}\right]^{0.5}
$$

Schmidt number $\left(\mathrm{N}_{\mathrm{Sc}}\right)$ was incorporated as the ratio of dynamic viscosity to that of kinematic viscosity of air at $54^{\circ} \mathrm{C}$.

A mass transfer co-efficient correction factor was incorporated in the model as,

$$
K_{g}=K_{g c} \times 1.652 \times 10^{-2}
$$

Dell workstation T5400 was used for running the finite element model simulation. Drying process simulation was carried out for 18000s.

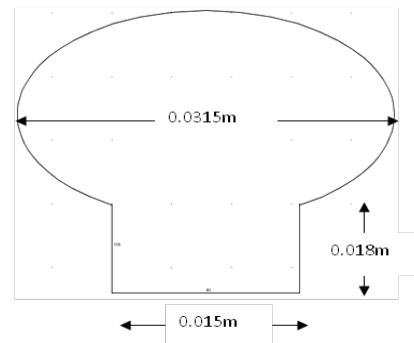

(a)

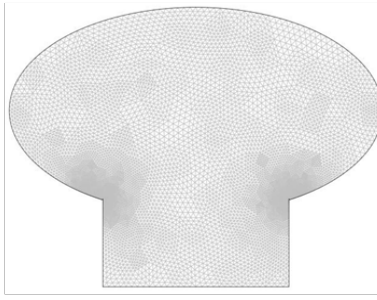

(b)
Figure 2 (a) Geometry. (b) Meshed geometry.

\section{Results and discussion}

The geometry of mushroom is axis-symmetric, therefore it can be said that the two and three-dimension model are equivalent with respect to shape and the transport phenomenon occurring. Moreover, the calculation time of the two-dimensional domain will be much lower than the three-dimensional domain. ${ }^{9}$

\section{Experimental validation of the model at $55^{\circ} \mathrm{C}$ (case $\mathrm{A}$ )}

The simulation predictions were compared with the experimental measurements of temperatures for mushroom drying process. The simulation results were in good agreement with the experimental results as shown in Figure 3. Initially, there is a high temperature gradient $(\Delta \mathrm{T})$ between the mushroom and air temperature due to which the rate of heat transfer to the mushroom is very high. As a result, steep rise in temperature of mushroom was observed initially, followed by steady state condition after 6600 s temperature. The difference in experimental and modeled temperature profile can be attributed to the combined effects of experimental and model assumptions viz., shrinkage is negligible, isotropic condition and thermal properties of materials.

Balaban $^{8}$ compared the effect of incorporation of shrinkage in food materials during drying and concluded that non consideration of shrinkage in simultaneous heat and mass transfer models can cause significant differences between the actual values of temperature and the results as predicted by the model. The same could be seen in this model. However, it was observed that as the time progresses the experimental temperature slowly approaches the modeled temperature thereby reducing the difference in modeled and experimental values. Ranjan et al. ${ }^{14}$ predicted drying behavior of banana by varying drying air temperature using finite element model without considering shrinkage effects, which resulted in good agreement with the experimental results.

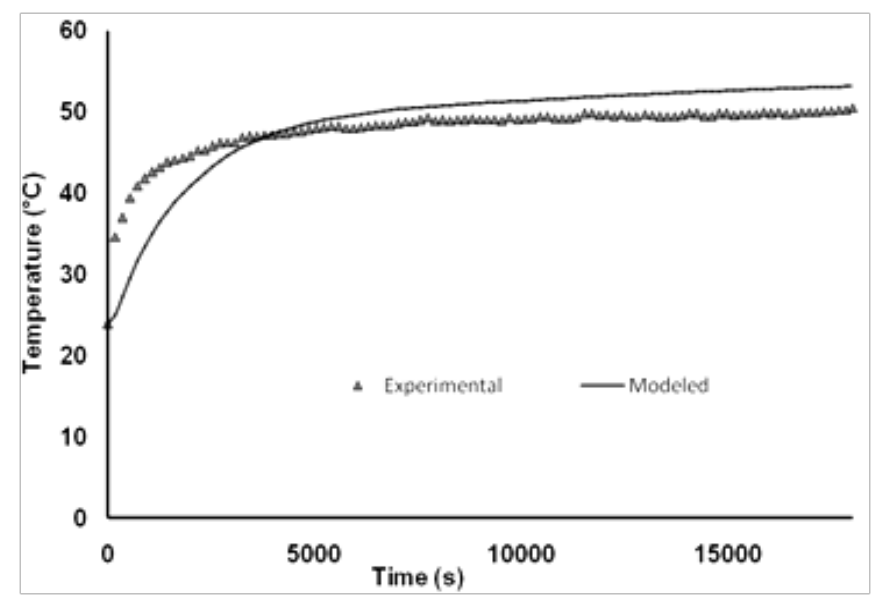

Figure 3 Validation of experimental and modeled temperature.

Figure 4 shows the variation of temperature with respect to time along five different points (as depicted points in Figure). It can be seen that the rise in temperature along all these points is almost the same. The temperature at points S1 and S2 are located in the stem of the mushroom and rises steeply. Heat transfer is inversely proportional to the surface area and the surface area of the head is more than that of the stem. Therefore, transfer of heat to the stem took place at a much faster rate than the mushroom head portion. This observation was same as reported earlier by Senadeera et al. ${ }^{15}$ that as the surface area increases, drying rate decreased at every drying temperature. The points $\mathrm{H} 1$ and $\mathrm{H} 3$ also show a steep rise due to their proximity to the boundary surface of the mushroom. However, $\mathrm{H} 2$ located at the centre of mushroom shows a gradual increase in temperature.
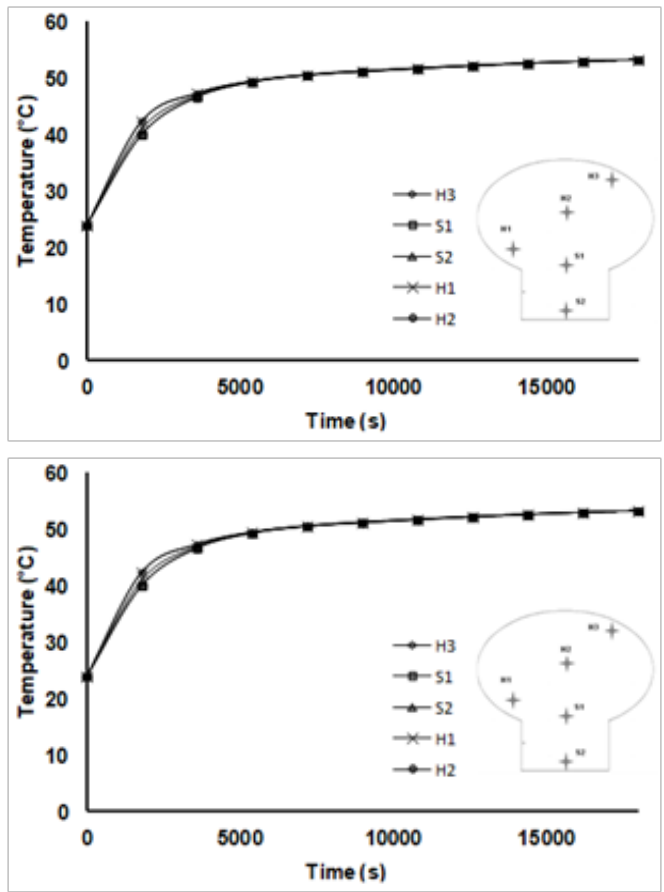

Figure 4 Variation of temperature along different points as depicted. 
Figure 5 shows that the predicted moisture content profiles are in close agreements with the experimental measurements. This clearly indicates that the model can be used effectively to predict the reduction in moisture content at different intervals of time during drying process. Figure 6 shows the variation of moisture content during drying at different intervals of time. As the drying time progresses heat penetrates towards the centre of the mushroom. This also results in simultaneous diffusion of moisture from the centre towards the surface of the mushroom.

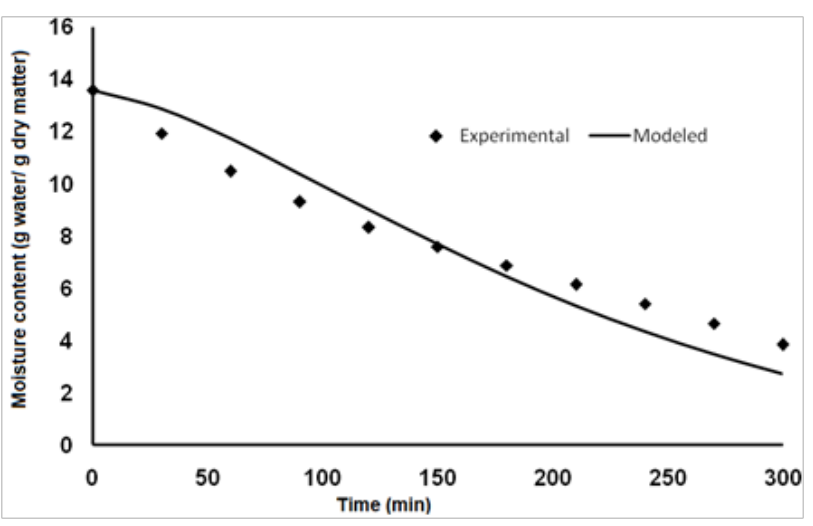

Figure $\mathbf{5}$ Validation of predicted moisture content profiles with experimental measurements.

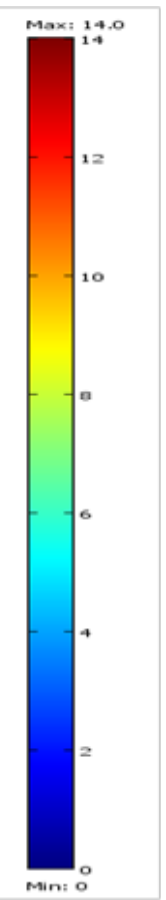

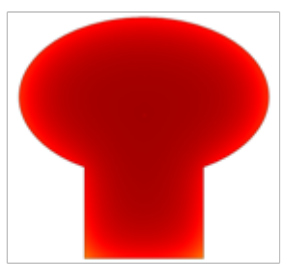

(a)

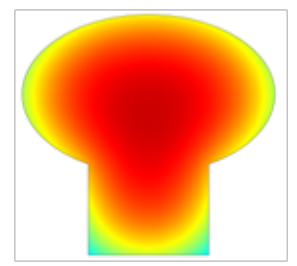

(c)

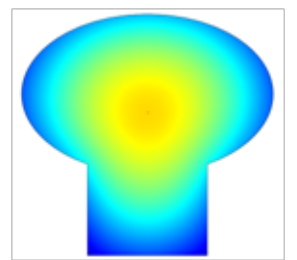

(e)

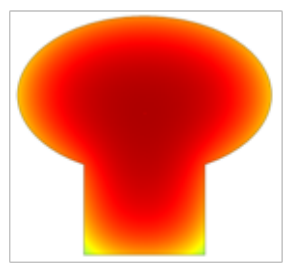

(b)

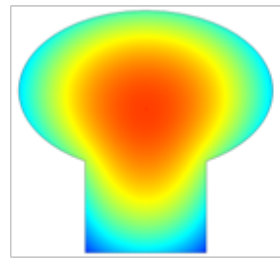

(d)

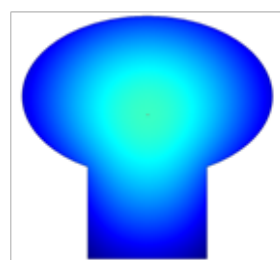

(f)
Figure 6 Predicted moisture content profile during drying of mushroom at $55^{\circ} \mathrm{C}$ with different time intervals of (a) I800s. (b) 3600 s. (c) 7200 s. (d) 10800 s. (e) I4400s. (f) I8000s

The slowest heating zone (SHZ) is defined as the region at which food product receives the least amount of heat during thermal processing. Tracking the slow heating zone (SHZ) is important to assess the effectiveness of any process involving heat transfer Padmavathi \& Anandharamakrishnan ${ }^{16}$ It was observed that the moisture content is highest at the geometric centre of the mushroom head for any time step as it also happens to be the slowest heating zone (SHZ).

The variation of moisture content of mushroom at 5 different points is depicted in Figure 7. From the Figure 7, it can be observed that the rate of drying is minimum at $\mathrm{H} 2$ and maximum at $\mathrm{H} 3$ as the transfer of moisture from the stem is faster than that of the head portion as mentioned earlier in the case of temperature. Also, it is found that the drying rate is almost the same for points $\mathrm{H} 1$ and $\mathrm{H} 3$ due to its proximity to the boundary surface. The drying rate is similar for $\mathrm{S} 1$ and $\mathrm{H} 2$ since $\mathrm{S} 1$ is located at the interface of the head and the stem. Thus, it can be concluded that diffusion controls the rate of drying and therefore is the rate limiting step. Since the model has already been validated with case $\mathrm{A}\left(\mathrm{T}_{\text {wall }}=55^{\circ} \mathrm{C}\right)$, it can be used to make predictions for drying at different temperatures. In this view, the following two case studies were performed with the same boundary conditions except for wall boundary condition as given below;

- $\quad$ Case B: $\mathrm{T}_{\text {wall }}=45^{\circ} \mathrm{C}$

- $\quad$ Case $\mathrm{C}: \mathrm{T}_{\text {wall }}=35^{\circ} \mathrm{C}$

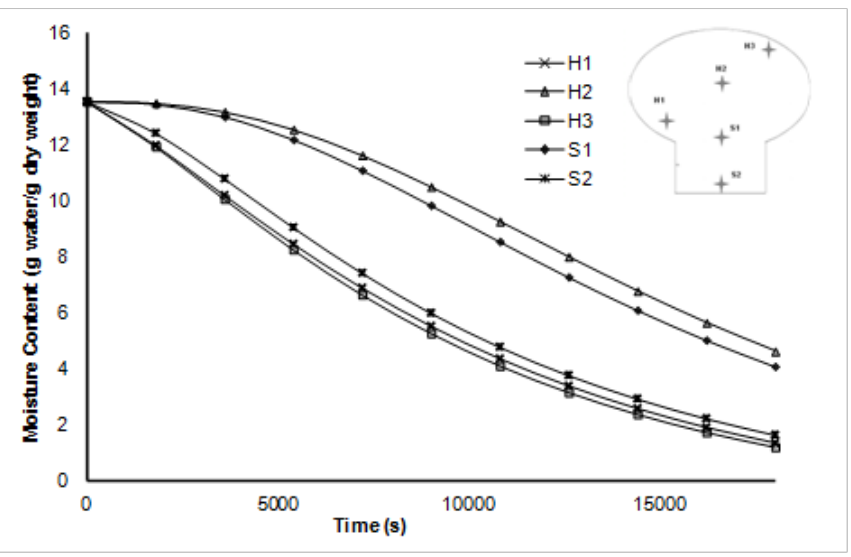

Figure 7 Variation of moisture along different points.

\section{Effect of drying air temperature on drying of mushroom}

In this study, effect of two different drying air temperatures (case $\mathrm{B}$ and case C) during drying were compared with case A. Figure 8 shows the variation of temperature profile for drying the product under conditions of Case A, Case B and Case C. It can be observed that in case $\mathrm{A}$, the product temperature reaches close to the ambient temperature. However, the difference in temperature of the product and the surrounding is maximum for case $\mathrm{C}$ during the same drying period. From this it can be observed that the rate of heat transfer is directly proportional to the temperature gradient $(\Delta \mathrm{T})$ across the boundary of mushroom. In Case A, the duration at which temperature reaches steady state condition is found to be less when compared to case $\mathrm{B}$ and Case $\mathrm{C}$ dried at lower temperatures. This is due to the fact that increase in air temperature increases the drying rate by improving evaporation rate with necessary heat of vaporization. Decreasing the drying air temperature gradually with respect to decrease in moisture content will result in maintaining constant evaporation rate throughout the process. ${ }^{17}$ Steady-state increase in temperature during 
drying at Case A, Case B, Case C begins after 6000s, 4200s and 2400s of drying time, respectively. Hence, Case A is considered to be more appropriate since the temperature of drying air should be quite high to remove the high moisture content in the product initially.

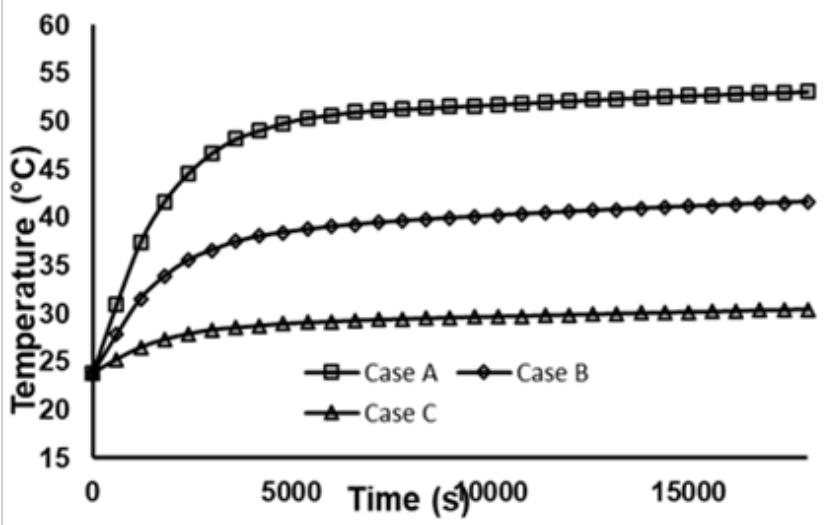

Figure 8 Temperature Profile for different drying temperatures of $55^{\circ} \mathrm{C}$ (Case A), $45^{\circ} \mathrm{C}$ (Case B), and $35^{\circ} \mathrm{C}$ (Case C).

The temperature and moisture profiles obtained above are comparable with the results of Ranjan et al. ${ }^{14}$ and it was found that there is not much significant difference in the trend of moisture profiles. Their model shows good agreement with the experimental results without considering shrinkage effects. Similar results were also observed when analyzing the drying behavior in various other vegetables such as carrot, garlic, onion, potato etc. ${ }^{18,19}$

Figure 9 gives the moisture profile for drying under case A, case B and case C. In case A, due to the lower relative humidity of air, partial vapor pressure of drying air becomes low which results in increased moisture evaporation rate. ${ }^{17}$ This indicates that, as the drying temperature increases, the rate of removal of moisture from the product also increases. The final moisture content after 18000 s of drying as predicted by the model for drying temperatures of case A, case $\mathrm{B}$ and case $\mathrm{C}$ are 3.32, 6.49 and 9.51 gram of water per gram dry matter, respectively. Thus, it can be concluded that the rate of drying is highly controlled by temperature of drying during the process.

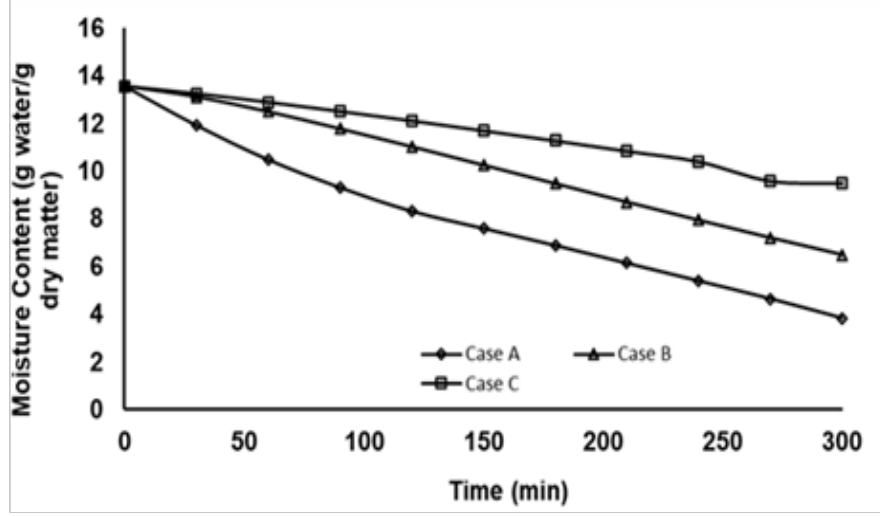

Figure 9 Moisture content profile for drying at different temperatures of $55^{\circ} \mathrm{C}$ (Case A), $45^{\circ} \mathrm{C}$ (Case B), and $35^{\circ} \mathrm{C}$ (Case C).

\section{Effect of moisture variations along axial and radial direction}

To study the variation of moisture within the mushroom along the radial as well as the axial direction, Moisture profiles were plotted for all the three cases (case A, case B and case C) with 3 different time steps.

\section{Radial direction}

Moisture profiles were plotted along the radial direction through the head of the mushroom as shown in Fig. 10. The variation of moisture content at various time intervals of $60 \mathrm{~s}, 600 \mathrm{~s}$, and $6000 \mathrm{~s}$ with respect to Case A, case B and case C are shown in Figure 10 respectively. The figure shows that at $60 \mathrm{~s}$ of drying, there is no considerable reduction in moisture content. But after $600 \mathrm{~s}$ of drying a small reduction in moisture content to around $13 \% \mathrm{db}$ from $13.5 \% \mathrm{db}$ was observed in all the cases at the boundary surface, and there was no reduction from the core of the mushroom. Further, after 6000s of drying the moisture level drops drastically to $7 \% \mathrm{db}$ in Case A, $9.9 \% \mathrm{db}$ in case B and $11.4 \%$ in case $\mathrm{C}$ at the boundary surface and also the moisture content inside the mushroom reduces due to the diffusion of moisture towards the surface. Thus, significant reduction in moisture content takes place after 600 s of drying and increases from mushroom surface to the inner core.
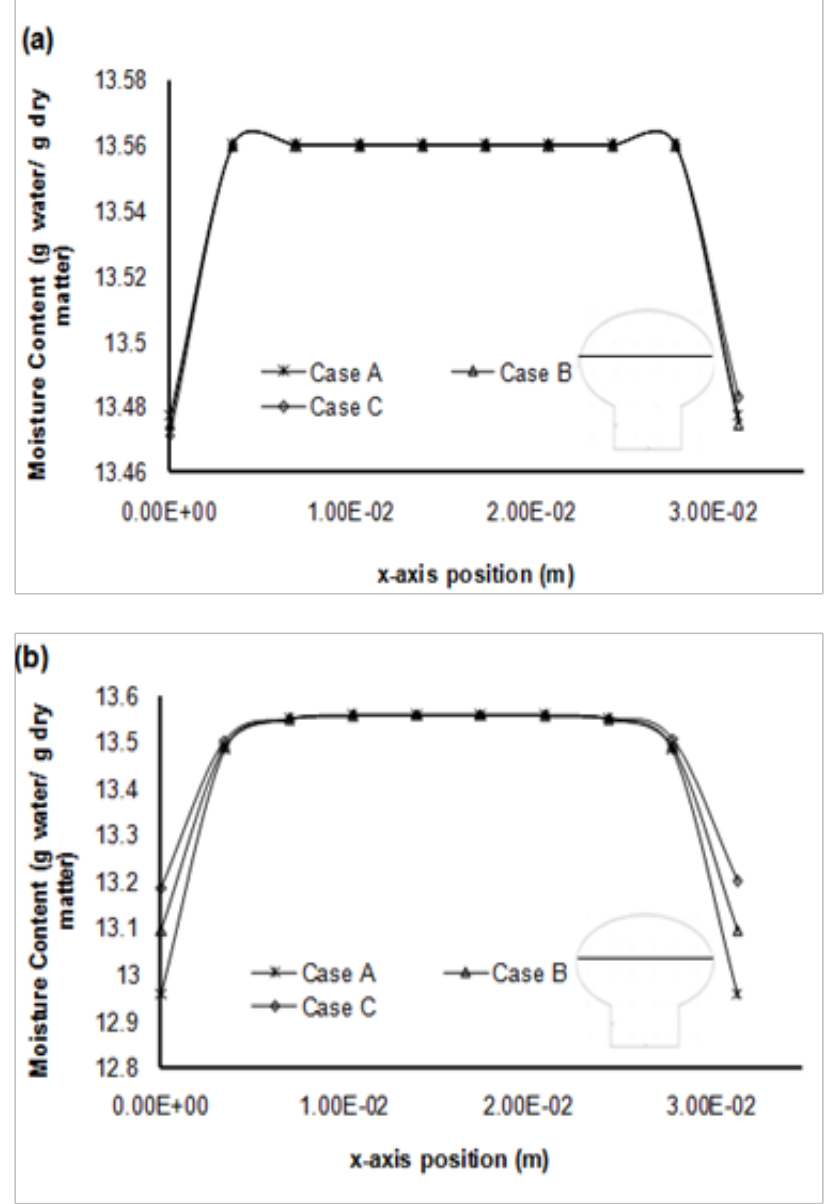


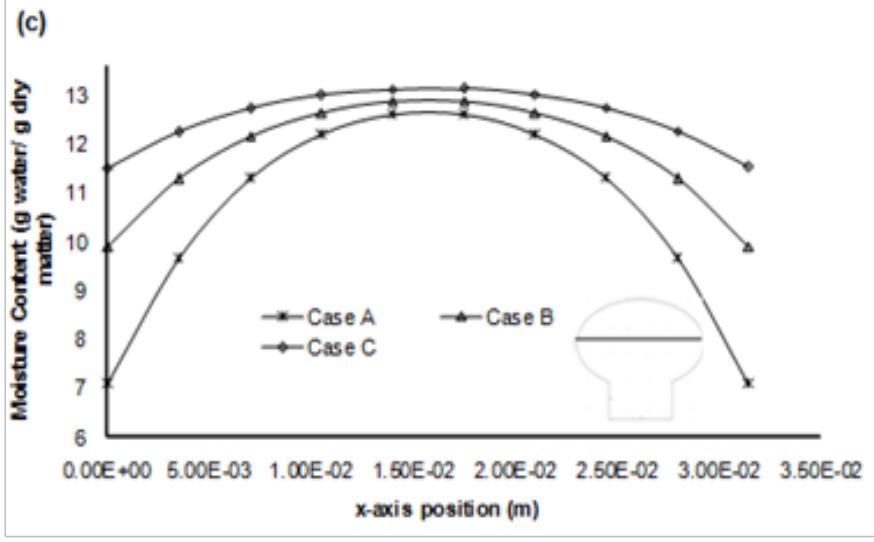

Figure 10 Moisture variation within mushroom along radial direction after (a) $60 \mathrm{~s}$. (b) $600 \mathrm{~s}$. (c) $6000 \mathrm{~s}$ at different drying temperatures of $55^{\circ} \mathrm{C}$ (Case A), $45^{\circ} \mathrm{C}$ (Case B), and $35^{\circ} \mathrm{C}$ (Case C).

\section{Axial direction}

Figure 11 demonstrates the variation of moisture content along the axial direction which pass through the head and stem of the mushroom for different drying temperatures (case A, case B, case C) at various time intervals of $60 \mathrm{~s}, 600 \mathrm{~s}$ and $6000 \mathrm{~s}$, respectively. The negative $\mathrm{y}-$ axis indicate the stem of the mushroom.

At 60 s of drying (Figure 11A) there is no considerable reduction in moisture content at the stem and head portions. After 600s of drying, stem showed slightly higher moisture content than head portion. However, Figure $11 \mathrm{C}$ indicates that after 6000 s of drying the moisture content of the stem is lesser than that of the head for all the cases. Further, it can be observed that the amount of moisture increases from the surface to the core of mushroom.
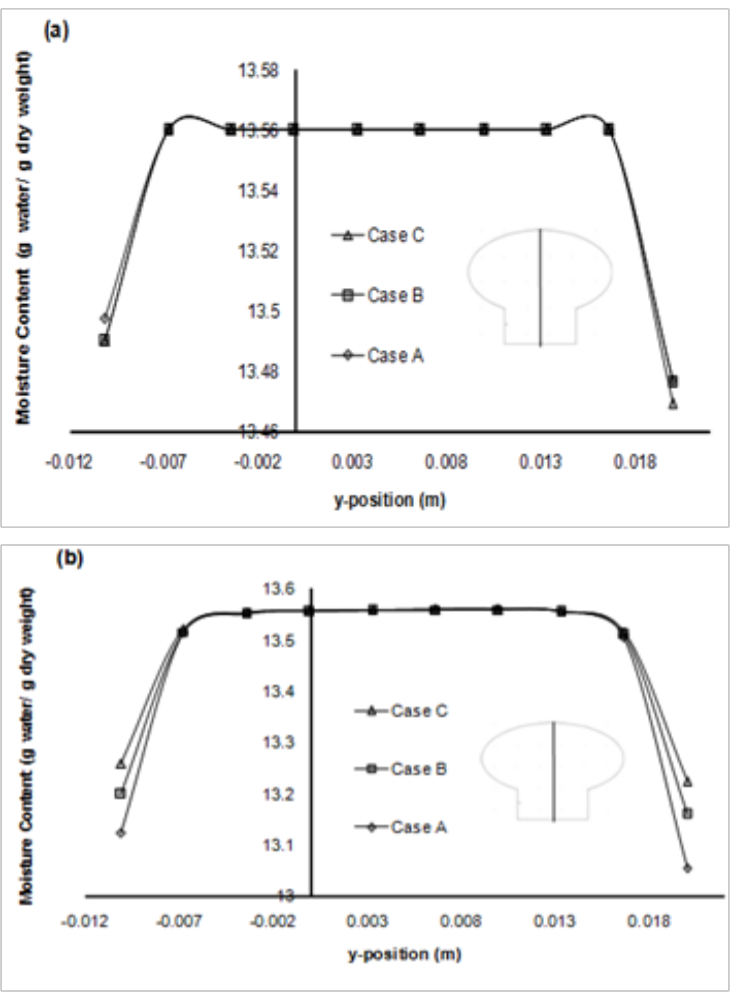

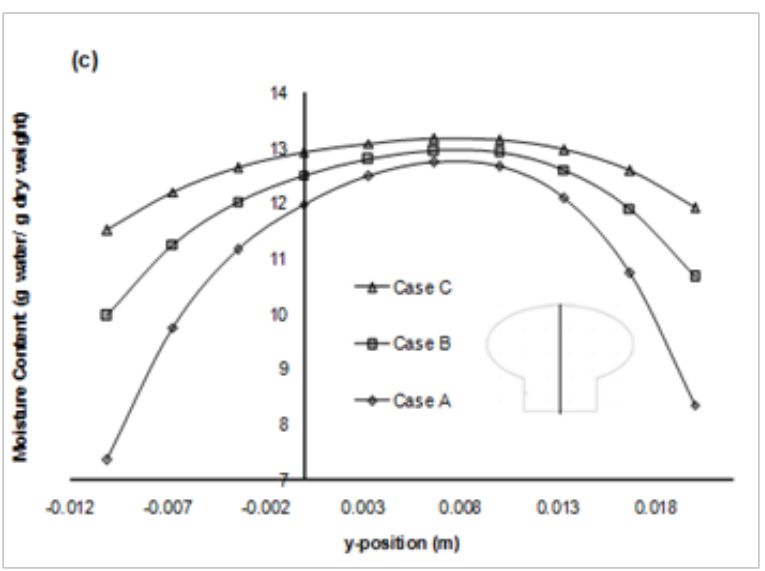

Figure I I Moisture variation within mushroom along axial direction after (a) 60 s. (b) 600 s. (c) $6000 \mathrm{~s}$ at different drying temperatures of $55^{\circ} \mathrm{C}$ (Case A), $45^{\circ} \mathrm{C}$ (Case B), and $35^{\circ} \mathrm{C}$ (Case C).

\section{Conclusion}

A two-dimensional finite element model was developed considering simultaneous heat and mass transfer for predicting moisture content during dehydration of mushroom. The phase change mechanism was incorporated in the model. Various factors, such as, heat transfer coefficient, mass transfer coefficient, water activity of the mushroom, specific heat, thermal conductivity, and diffusion coefficient, etc., were incorporated into the model for better predictions of transport processes. The developed model was validated with the experimental measurements of temperature and moisture content. The model was extended to investigate the moisture content variation and temperature profile for different temperatures $\left(35^{\circ} \mathrm{C}\right.$, $45^{\circ} \mathrm{C}$ ). The temperature profile for increase in temperature showed that the rise in temperature is directly proportional to the difference in temperature between the product and the surrounding $(\Delta \mathrm{T})$. It was found that for drying at $35^{\circ} \mathrm{C}, 45^{\circ} \mathrm{C}, 55^{\circ} \mathrm{C}$ steady-state increase in temperature begins after $2400 \mathrm{~s}, 4200 \mathrm{~s}$, and $6000 \mathrm{~s}$ of drying time, respectively. Also, after 5hours of drying, maximum loss of moisture was obtained when drying at $55^{\circ} \mathrm{C}$ and the lowest loss of moisture was found in $35^{\circ} \mathrm{C}$. Final moisture content after $35^{\circ} \mathrm{C}, 45^{\circ} \mathrm{C}$ and $55^{\circ} \mathrm{C}$ was $9.51,6.49$, 3.32gram water/gram dry matter, respectively. Thus, the developed model was used to determine the processing time of mushroom at different temperatures $\left(35^{\circ} \mathrm{C}, 45^{\circ} \mathrm{C}, 55^{\circ} \mathrm{C}\right)$ for long term storage depending upon the usage. This model can be extended to other vegetables and can help in predicting the temperature and moisture profile of the product and thus help in producing processed food of highest quality.

\section{Acknowledgements}

The authors thank the Director, CSIR-CFTRI for providing the lab facility and support for conducting this research.

\section{Conflict of interest}

The authors declare that there is no conflict of interest.

\section{References}

1. Erik Torringa, Erik Esveld, Ischa Scheewe, et al. Osmotic dehydration as a pre-treatment before combined microwave-hot-air drying of mushrooms. J Food Eng. 2001;49(2-3):185-191. 
2. Rama V, John PJ. Effects of methods of drying and pretreatments on quality of dehydrated mushroom. Indian Food Pack. 2000;54:59-64.

3. Giri SK, Prasad S. Drying kinetics and rehydration characteristics of microwave-vacuum and convective hot-air dried mushrooms. J Food Eng. 2007;78(2):512-521.

4. Walde SG, Velu V, Jyothirmayi T, et al. Effects of pretreatments and drying methods on dehydration of mushroom. J Food Eng. 2006;74(1):108-115.

5. Ghiaus AG, Margaris DP, Papanikas DG, et al. Mathematical Modeling of the Convective Drying of Fruits and Vegetables. J Food Sci. 1997;62(6):1154-1157.

6. Wang N, Brennan JG. A mathematical model of simultaneous heat and moisture transfer during drying of potato. J Food Eng. 1995;24(1):47-60.

7. Balaban M, Pigott G. Mathematical Model of Simultaneous Heat and Mass Transfer in Food with Dimensional Changes and Variable Transport Parameters. J Food Sci. 1988;53(3):935-939.

8. Balaban M. Effect of Volume Change in Foods on The Temperature and Moisture Content Predictions of Simultaneous Heat and Moisture Transfer Models. J Food Process Eng. 1990;12(1):67-88.

9. Lespinard AR, Goñi SM, Salgado PR, et al. Experimental determination and modelling of size variation, heat transfer and quality indexes during mushroom blanching. J Food Eng. 2009;92:8-17.

10. Zanoni B, Peri C, Gianotti R. Determination of the thermal diffusivity of bread as a function of porosity. J Food Eng. 1995;26(4):497-510.

11. Boukouvalas CJ, Bisharat GI, Krokida MK. Structural Properties of Vegetables During Air Drying. Int J Food Prop. 2010;13(6):1393-1404.
12. Murumkar RP, Jain SK, Pilaskar PS, et al. Osmo-Fluid Bed Drying of White Button Mushroom. Bioved-An International Bi-Annual Journal of Life Science. 2007;18:47-52.

13. Yang H, Sakai N, Watanabe M. Drying Model with Non-Isotropic Shrinkage Deformation Undergoing Simultaneous Heat and Mass Transfer. Dry Technol. 2001;19(7):1441-1460.

14. Ranjan R, Irudayaraj J, Reddy JN, et al. Finite-Element Simulation and Validation of Stepwise Drying of Bananas. Numer Heat Transf Part Appl. 2001;45(10):997-1012.

15. Senadeera W, Bhandari BR, Young G, et al. Influence of shapes of selected vegetable materials on drying kinetics during fluidized bed drying. $J$ Food Eng. 2003;58(3):277-283.

16. Padmavati R, Anandharamakrishnan C. Computational Fluid Dynamics Modeling of the Thermal Processing of Canned Pineapple Slices and Titbits. Food Bioprocess Technol. 2013;6(4):882-895.

17. Islam MR, Ho JC, Mujumdar AS. Convective Drying with Time-Varying Heat Input: Simulation Results. Dry Technol. 2003;21(7):1333-1356.

18. Souraki BA, Andrés A, Mowla D. Mathematical modeling of microwaveassisted inert medium fluidized bed drying of cylindrical carrot samples. Chem Eng Process Process Intensif. 2009;48(1):296-305.

19. Krokida MK, Karathanos VT, Maroulis ZB, et al. Drying kinetics of some vegetables. J Food Eng. 2003;59(4):391-403. 